\title{
Treatment of Young People with Dental, Jaw and Face Deformation as a Challenge for Their Psycho-Social Rehabilitation
}

\author{
Doctor Ajshe Rexhep \\ Orthodontist, Universital Dental Clinic "St Pantelejmon"- Skopje \\ PhD Hava Rexhep \\ Social Politics, Ministry of social labor, Department of Ohrid
}

Doi:10.5901/ajis.2015.v4n1s2p17

\begin{abstract}
Aim: To investigate how good is the dental-orthodontic treatment of the young people with face deformation, and it contributes in improving dental function and normal straight face profile. Materials and methods: Different young people with dental midline, jaw deviation and face deformation will be presented. The method used is fixed orthodontic appliance, technique of straight wire appliance. Results: The good results of the treatment clearly demonstrate how the previous used method improve the psycho-social rehabilitation of the young people. After that they showed their satisfaction and stated that they are very happy about the successful therapy which significantly have changed their lives. Conclusion: The research has shown that all the results of this treatment provoke a better further rehabilitation from the social and psychological aspect.
\end{abstract}

Keywords: esthetic, psychosocial problem, young people, treatment, orthodontics

\section{Introduction}

The healthy and normal life is very important for every human being especially it is crucial for the young people. Nowadays, the beauty and the smile are a very significant influence of the young people healthy social and private life. We are witnesses of how they are spending lots of money on make-up, cosmetics, plastic surgeries and many expensive products in order to make themselves even more beautiful. This helps them to be more self confident and gives them motivation. The beauty of the face according to the previous facts is more than important and we can say it is crucial for healthy and motivated youth. Treatment of young people with dental, jaw and face deformation is very challenging for their psycho-social rehabilitation and at the same time it is a very interesting field for a research to be done.

Fixed orthodontic appliance have been applied for treatment of various malocclusion. Using digital manipulation of hard and soft tissue smile components (attractiveness) were objectives for qualifying and comparing ideal norms for a good smile. The paradigm shift from occlusion towards soft tissues and smile esthetics emphases dental structures and the surrounding soft tissue envelope. Also, establishing ideal function and esthetics may be mutually exclusive and require consideration as to what trade of this are acceptable in the pursuit of the normal smile objective.

\section{Aim}

The main aim of this case study is to investigate and demonstrate the effects and challenges of the orthodontic treatment of patients with dental facial anomalies reflected in their social and psychological life. deviations.

The case reports defines successfully treatment of some anomalies associated with dental jaws and face

\section{Participants}

In order to investigate the topic as a participants are included 20 patients, age ranged between 13 and 19 years old. The investigation is done in the University Dental Clinical Centre St. Pantelejmon, in Skopje. The patients were complaining on their faces deformations gained by dental crowding.

Frontal and lateral pho to of some patients (female and male) were analyzed before and after orthodontic 
treatment. Patients were recorded with diagnosed malocclusion in permanent dentition and no previous orthodontic treatment.

\section{Material and Methods}

Different young people with dental midline, jaw deviation and face deformation are presented. The method used is fixed orthodontic appliance, technique of straight wire appliance and associated with cursive elastics which were taken all over 24 hours a day. The fixed orthodontic appliance is treated for nearly 24 months with a regular monthly controls. Also it will be done an investigation by a leading interview.

\section{Results}

After the treatment period the participants were interviewed in order to find out their personal feelings and opinion related to this treatment.

The good results of the treatment clearly demonstrate how the previous used method improve the psycho-social rehabilitation of the young people. After that they showed their satisfaction and stated that they are very happy about the successful therapy which significantly have changed their lives.

After the treatment they feel more self confident, more motivated and more sociable. They emphasized that the physical appearance is really important factor which influence the behavior and the social life of the young people.

Here is one particular patient treated and the results before and after the treatment.
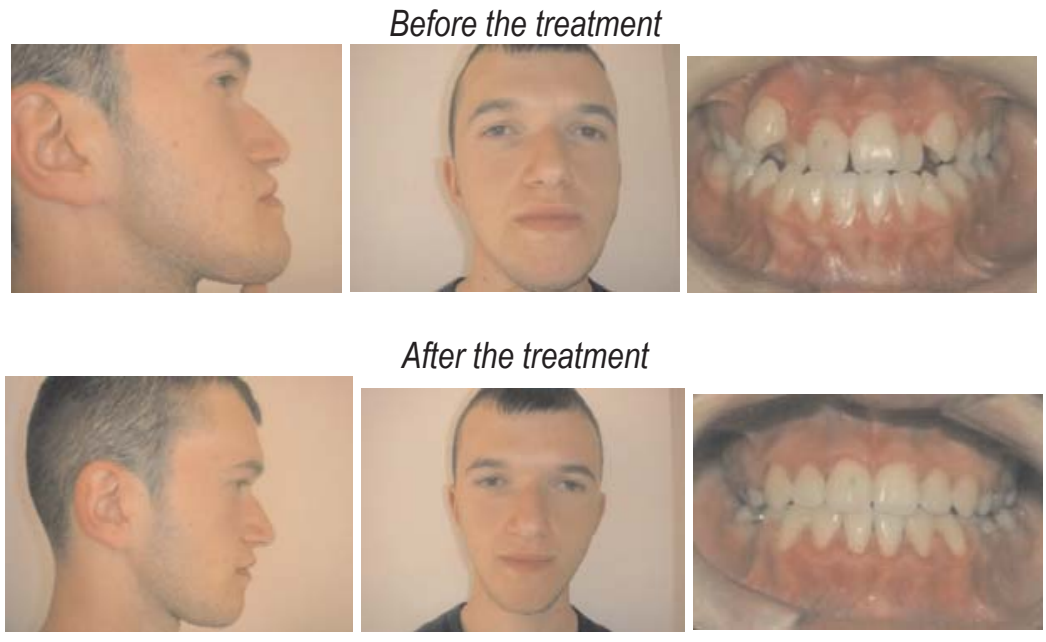

\section{Conclusion}

The research has shown that all the results of this treatment provoke a better further rehabilitation from the social and psychological aspect. The patients admitted that they feel really happy after the treatment, also more self confident. They claimed that the treatment helped them to be more social, and not shy because of the physical appearance.

From all the previous, we can conclude that the treatment of young people with dental, jaw and face deformation enhanced their psycho-social rehabilitation, and also it has an incredible influence on their social behavior and social function.

\section{References}

Clark JR, Hutchinson I, Sandy JR. Funcional occlusion: The role of articulators in orthodontics. J Orthod 2001.

Poop TW, Gooris CGM, Schur AJ. Nonsurgical treatment for Class III dental relationship: a case report Am J Orthod Dentofac Orthop 1993; 103: 203-11.

Guyer EC, Ellis EE, Mc. Namara JA Jr, Bahrents RG. Components of Class III malocclusion in juveniles and adolescents. Angle Orthod 1986; 56: 7-30.

Williams S, Andersen CE. The morphology of the potential Class III skeletal pattern in the growing child. Am J Orthod Dentofac Orthop 1986; 89: 302-11. 